\title{
The Consequences of Chloride-Induced Corrosion on Steel Bar and Reinforced Concrete Structures
}

\section{Charis Apostolopoulos*}

Laboratory of Technology and Strength of Materials, University of Patras, Greece

It is widely known that corrosion of steel reinforcement is one of the most important durability issues in reinforced concrete design [1]. The corrosion phenomenon can be initiated due to chloride ingress in concrete or due to depassivation of the protective thin oxide film of the steel reinforcement, through the action of carbon dioxide from the atmosphere. The corrosion activity degrades not only the appearance of the structure, but also its strength and safety, with the subsequent reduction in the cross sectional area, the strength and ductility properties of the reinforcement and with the decrease of bond with the surrounding concrete $[2,3]$. In coastal regions where high chloride concentrations are encountered, chloride-induced corrosion is the major source of environmental deterioration of reinforced concrete structures.

Chlorides that reach the concrete surface, enter the pore system either by diffusion (in stationary pore water), or by capillary suction of the surface water in which they are dissolved (or by combination of both transport mechanisms).

Chloride attack is distinct in that its primary action is the corrosion of steel reinforcement and only as a consequence of the corrosion process the surrounding concrete is damaged. Corrosion propagation is taking place at a rate that depends on the availability of both oxygen and water at the cathode. However, even at low rates of $\mathrm{O}_{2}$, severe pitting corrosion has been noticed. It can be attributed to the fact that the anodic sites may be localized but the corresponding cathodic sites may be spread out over a wide area [1,4-7]. In this way, as the corrosion product is discouraged from precipitation, and due to the existence of highly active and localized anodic sites, a severe pitting corrosion may occur without an earlier warning through visible signs at the surrounding concrete. This can lead to rapid loss of the load bearing capacity of the reinforced concrete member.

The majority of the related studies on the effects of corrosion refer to steel bars directly exposed to the corrosive environment (bare bars), usually under salt-spray exposure $[8,9]$. Aspects, as the subsequent mass loss, the depth and the density of the pits formed on its surface are usually evaluated.

What is however neglected to a great extent, even by the appropriate standards, is the evaluation of how the accumulated corrosion alters the mechanical properties of the steel bar. In the relevant national standard as well as in the other appropriate European National Standards, the ability of a steel bar for mechanical performance is considered as being unchanged during the entire lifetime of a reinforced concrete structure. Even though it is early recognized that chloride induced corrosion, characterized by the continuous occurrence of pitted regions on the steel reinforcement, it leads to substantial reductions in the bar crosssection. Such type of damage can have significant effects on strength and ductility of reinforced concrete elements especially in dual-phase steel of high yield and ductility demand [2,3,8-15]. Existing design codes for steel reinforced structures do not take into consideration the accumulated material damage due to corrosion since they are unable to quantify it and need further review.
Given the above, apart from a few valid efforts investigations on the effects of corrosion on the mechanical performance of reinforcing, steel bars remains rare. To this extent, the influence of accumulated corrosion damage of steel bars embedded in concrete on the reduction of bond strength between bar and concrete has been investigated and assessed [2,3,8-15].

The frame degradation of a structure from reinforced concrete (i.e. bridges) that is located within an earthquake prone region and a coastal environment seems to be time dependant, since the damage accumulation due to corrosion as much as the damage accumulation due to low cycle fatigue are time dependant functions. Based on the damage accumulation in steel, the reconsideration of useful life appears to be necessary as the possible exceed of damage can seriously affect the integrity of structures.

In all events, the evaluation of the strength and design of corroded steel using the properties of original material may lead to over-design and erroneous results with potential catastrophic results.

\section{References}

1. Gonzalez JA, Feliu S, Rodriguez P, Ramirez E, Alonso C, et al. (1996) Some questions on the corrosion of steel in concrete - Part 1: when, how and how much steel corrodes. Mater Struct 29: 40-46.

2. Demis S, Pilakoutas K, Apostolopoulos CA (2010) Effect of corrosion on bond strength of steel and non-metallic reinforcement. Mater Corros 61: 328-331.

3. Batis G, Rakanta E (2005) Corrosion of steel reinforcement due to atmospheric pollution. Cement Concrete Comp 27: 269-275.

4. Ozbolt J, Balabanic G, Periskic G, Kuster M (2010) Modelling the effect of damage on transport processes in concrete. Constr Build Mater 24: 1638-1648.

5. Papadakis VG (2000) Effect of supplementary cementing materials on concrete resistance against carbonation and chloride ingress. Cement Concrete Res 30: 291-299.

6. Shi X, Xie N, Fortune K, Gong J (2012) Durability of steel reinforced concrete in chloride environments: An overview. Constr Build Mater 30: 125-138.

7. Neville A (1995) Chloride attack of reinforced concrete: An overview. Mater Struct 28: 63-70.

8. Apostolopoulos CA, Papadopoulos MP, Pantelakis SG (2006) Tensile Behaviour of Corroded Reinforcing Steel Bars BSt 500s. Constr Build Mater 20: 782-789.

9. Apostolopoulos CA (2007) Mechanical behavior of corroded reinforcing steel bars S500s tempcore under low cycle fatigue. Constr Build Mater 21: 14471456.

*Corresponding author: Charis Apostolopoulos, Assistant Professor, Laboratory of Technology and Strength of Materials, University of Patras, Greece, E-mail: charrisa@mech.upatras.gr

Received August 22, 2012; Accepted August 24, 2012; Published August 27 , 2012

Citation: Apostolopoulos C (2012) The Consequences of Chloride-Induced Corrosion on Steel Bar and Reinforced Concrete Structures. J Appl Mech Eng 1:e109. doi:10.4172/2168-9873.1000e109

Copyright: (c) 2012 Apostolopoulos C. This is an open-access article distributed under the terms of the Creative Commons Attribution License, which permits unrestricted use, distribution, and reproduction in any medium, provided the original author and source are credited. 
Citation: Apostolopoulos C (2012) The Consequences of Chloride-Induced Corrosion on Steel Bar and Reinforced Concrete Structures. J Appl Mech Eng 1:e109. doi:10.4172/2168-9873.1000e109

Page 2 of 2

10. Capozucca R (1995) Damage to reinforcement concrete due to reinforcement corrosion. Constr Build Mater 9: 295-303.

11. Fang C, Lungren K, Chen L, Zhu C (2004) Corrosion influence on bond in reinforced concrete. Cement Concrete Res 34: 2159-2167.

12. Apostolopoulos CA (2009) The Influence of Corrosion and Cross-Section Diameter on the Mechanical Properties of B500c Steel. J Mater Eng Perform 18: 190-195.
13. Apostolopoulos CA, Papadakis VG (2008) Consequences of steel corrosion on the ductility properties of reinforcement bar. Constr Build Mater 22: 2316-2324.

14. Cairns J, Plizzari GA, Du Y, Law DW, Frnazoni C (2005) Mechanical properties of corrosion-damaged reinforcement. ACI Mater J 102: 256-264.

15. Papadopoulos MP, Apostolopoulos CA, Zervaki AD, Haidemenopoulos GN (2011) Corrosion of Exposed Rebars, Associated Mechanical Degradation and Correlation with Accelerated Corrosion Tests. Constr Build Mater 25: 33673374 . 